\title{
The team briefing: setting up relational coordination for your resuscitation
}

\author{
Eve Purdy ${ }^{1,2}$, Charlotte Alexander ${ }^{2}$, Rebecca Shaw ${ }^{2}$, Victoria Brazil ${ }^{2,3}$ \\ 'Department of Emergency Medicine, Queen's University, Kingston, ON, Canada \\ ${ }^{2}$ Emergency Department, Gold Coast University Hospital, Southport, OLD, Australia \\ ${ }^{3}$ Faculty of Health Sciences and Medicine, Bond University, Robina, QLD, Australia
}

\section{INTRODUCTION}

"Ring. Ring..." You watch the charge nurse, James, pick up the paramedic patch phone. He listens intently then replies, "alright, see you soon." James tells you that paramedics are ten minutes out with a 77-year-old male driver from a motor vehicle collision at highway speeds. The patient has obvious head and chest injuries, is GCS 13 and hemodynamically stable. The trauma alert is activated and the team starts to gather...how do you prepare?

The concept of briefing resuscitation teams is not novel, but there has been renewed energy towards improving those briefings as better understanding of team behaviours and non-clinical resuscitation skills have emerged..$^{1-4}$ Effective briefings have reduced mortality in surgical patients and have been shown to reduce the time to critical team tasks within a simulated resuscitation environment. ${ }^{5,6}$ One proposed mechanism for benefit is the construction of a "shared mental model" amongst team members. ${ }^{2,4}$ In a recent publication in Clinical and Experimental Emergency Medicine, Reid et al. advocated for the incorporation of the "zero-point survey" (ZPS) as an antecedent to the longstanding and familiar primary survey. The ZPS includes consideration of personal and environmental factors as well as a critical team component, the briefing. ${ }^{4}$ The authors associated with the ZPS humbly acknowledged a lack of empirical evidence for which to support their approach. We thought we might further explore and support the theoretical footing.

In this commentary we apply a macro-organizational theory, relational coordination, to a micro-level issue, caring for a single patient, to explore team briefings. We use experience from a large ethnographic study of a trauma service to support the concept of team briefings in the resuscitation setting for reasons that relate to, but go beyond, the "shared mental model."

\section{RELATIONAL COORDINATION THEORY}

Relational coordination theory describes factors that facilitate optimal work in high functioning organizations. ${ }^{78}$ The theory, usually applied between large groups at an organizational level, specifies three attributes of relationships within organizations that support coordination: shared goals that transcend specific functional task-related goals, shared knowledge that enables team members to understand how their tasks interrelate with others, and mutual respect that allows members to overcome status barriers and positively regard the work of others. These relational attributes are reinforced by communication that is timely, frequent, accurate, and problem solving-based. Relational coordination has been found to be particularly critical in situations where
eISSN: 2383-4625

Received: 6 March 2019

Revised: 15 April 2019

Accepted: 15 April 2019

Correspondence to: Eve Purdy Department of Emergency Medicine, Queen's University, 76 Stuart Street, Kingston, ON K7L 2V7, Canada E-mail: epurdy@qmed.ca ORCID

http://orcid.org/0000-0002-8098-5377

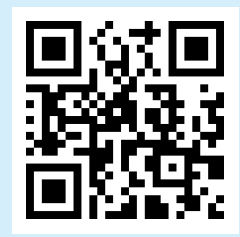

How to cite this article:

Purdy E, Alexander C, Shaw R, Brazil V. The team briefing: setting up relational coordination for your resuscitation. Clin Exp Emerg Med 2020;7(1):1-4.

This is an Open Access article distributed under the terms of the Creative Commons Attribution Non-Commercial License (http:// creativecommons.org/licenses/by-nc/4.0/). 
teams are faced with high levels of task interdependence, uncertainty, and time constraint. ${ }^{8}$

\section{MACRO RELATIONAL COORDINATION IN TRAUMA}

Recently, we undertook a study of relational coordination and the culture of trauma care at Gold Coast University Hospital, a large tertiary care and trauma centre in Australia. ${ }^{10}$ Data was collected using a quantitative relational coordination survey in conjunction with an ethnography-participant observation, interviews, and working groups-with the trauma service. The study was approved by the Gold Coast University Hospital ethics review board (HREC/18/0GC/13).

The overall picture from the quantitative measurement of the relational coordination index was that of strong team relationships at the macro level between groups, with some room for improvement. We presented data back to all those involved in trauma care and have since been working with providers from across disciplines to design and implement interventions targeted specifically at improving relational coordination. These range from simple fixes such as facilitating shared access to imaging, to simulations designed with radiographers to improve the ability to get to computed tomography fast and safe, to the development of a trauma code of conduct. We were the first to apply relational coordination to a hyperacute medical setting and the construct appeared to fit well. We were especially happy with how the process of measuring relational coordination facilitated engagement in a quality improvement process that spanned across organizational boundaries.

However, our simultaneously performed ethnography of trauma care left us with more questions than answers, particularly as it exposed significant variability across individual resuscitation cases. Despite strong macrolevel relational coordination, there was obvious inconsistency in what providers were experiencing on the front lines.

\section{THE TEAM BRIEFING AND MICRO RELATIONAL COORDINATION}

To explore further, we had participants describe trauma cases that went well and trauma cases that went poorly. Interestingly, we received few responses that focused on the severity of the patient's clinical condition or on the skill of those present in the room. What emerged most glaringly was the integral role of a team briefing in facilitating microlevel relational coordination at the point of care between members of an ad hoc team. The role of team briefing featured prominently in the narratives of trauma re- suscitations that went well. For example, participants told us that in a resuscitation that went well:

"roles [were] allocated prior to patient arrival, [we] discussed likely issues with the patient and how we would manage them+ likely sequence of events prior to patients' arrival."

"[there was] clear role allocation prepatient arrival with flexibility within role to redistribute workload once clinical condition known/changed."

"[there] was enough prep time given, [we were] able to fully prepare the team...time to prepare all drugs and infusions. Ability to preempt where we felt the resuscitation would go after stabilization."

"Teams [are] given heads up early so they can plan what to happen and patient priorities. Able to coordinate what to happen first and a clear plan before patient arrival so can be implemented quickly and efficiently."

This theme of effective team briefings dramatically surpassed any other identified factor such as time of day or availability of resources. Perhaps unsurprisingly, mutual respect (or a lack thereof) and competing priorities were predominant features of resuscitations gone poorly, however, responses that flagged the lack of a team briefing in these situations was also notable.

Our research team began to appreciate that the same domains that we were studying at the macro level to understand performance between groups of people within an organization were exactly the same factors that made the team briefing so important at the micro level. Based on this data, we hypothesize that high quality team briefings facilitate the rapid development of relational coordination between individual providers at the single patient level. While this supposition was established in the context of observations from traumas, we feel it can be reasonably extrapolated to the resuscitation of any critically ill patient.

\section{OPTIMIZING YOUR TEAM BRIEFING TO MAXIMIZE MICRO RELATIONAL COORDINATION}

We propose that the structure of the team briefing can influence the development of relational coordination in an ad hoc team. Fig. 1 illustrates how the team briefing model, adapted from a model proposed by Hicks and Petrosoniak, ${ }^{1}$ deliberately facilitates the creation of relational coordination prior to, or at the arrival of, a critically unwell patient.

Our team feels so strongly about the potential benefit of this approach that we have implemented rehearsals of the team briefing each morning in an exercise called "OneTeam Practice"- 


\section{Briefing Phase RC Domain Target}

\begin{tabular}{|c|c|}
\hline $\begin{array}{l}\text { Introductions } \\
\text { - Thank the team for coming } \\
\text { - Ask for the names and ensure that } \\
\text { they are visible throughout the } \\
\text { resuscitation (written on gowns, } \\
\text { name tags) }\end{array}$ & $\begin{array}{l}\text { This phase facilitates MUTUAL } \\
\text { RESPECT between members of the } \\
\text { team. When the leader explicitly } \\
\text { demonstrates each team member is } \\
\text { valued this can be incorporated as a } \\
\text { team belief. The tone for the degree of } \\
\text { MUTUAL RESPECT expected throughout } \\
\text { the case. }\end{array}$ \\
\hline $\begin{array}{l}\text { What we know } \\
\text { - Share relevant and available case } \\
\text { details such as age, case details, and } \\
\text { last vitals } \\
\text { - Synthesize what this information } \\
\text { means for the team }\end{array}$ & $\begin{array}{l}\text { The second phase lays the groundwork } \\
\text { of SHARED KNOWLEDGE between all } \\
\text { members of the team, as it pertains to } \\
\text { the specific case. }\end{array}$ \\
\hline $\begin{array}{l}\text { What we expect } \\
\text { (plan A) } \\
\text { - Given those relevant details, } \\
\text { outline what we expect to happen } \\
\text { in the first } 10 \text { minutes } \\
\text { - Set patient care priorities }\end{array}$ & $\begin{array}{l}\text { The third phase identifies SHARED } \\
\text { GOALS for members of the team. While } \\
\text { individuals will be charged with specific } \\
\text { tasks, they will have a better } \\
\text { understanding of how those tasks fit into } \\
\text { the bigger picture of caring for the } \\
\text { patient. }\end{array}$ \\
\hline $\begin{array}{l}\text { What might change } \\
\text { (plan B/C) } \\
\text { - Given what we know what could go } \\
\text { wrong or change? } \\
\text { - Briefly discuss patient care } \\
\text { priorities in those circumstances }\end{array}$ & $\begin{array}{l}\text { The fourth phase creates SHARED } \\
\text { KNOWLEDGE about potential } \\
\text { complications - which makes changing } \\
\text { direction and associated SHARED } \\
\text { GOALS easier, if needed. }\end{array}$ \\
\hline \begin{tabular}{l}
\multicolumn{1}{c}{ Roles } \\
- Assign specific roles \\
- Ask each member to briefly run \\
through their role to identify any \\
forseeable problems \\
- Identify and pair groups of people \\
who are a functional team
\end{tabular} & $\begin{array}{l}\text { This phase translates SHARED } \\
\text { KNOWLEDGE, as it relates to other } \\
\text { team members' roles, not the patient } \\
\text { specific details. We know that mutual } \\
\text { role understanding is an integral aspect } \\
\text { of implicit coordination. }\end{array}$ \\
\hline $\begin{array}{l}\text { Suggestions/Concerns } \\
\text { - Though open to suggestions } \\
\text { throughout the briefing, directly } \\
\text { solicit thoughts from the team by } \\
\text { asking a question such as, "this is a } \\
\text { complicated case, what have I } \\
\text { missed?" }\end{array}$ & $\begin{array}{l}\text { This final phase further supports } \\
\text { MUTUAL RESPECT by signalling that } \\
\text { input is valued. It lays the foundation for } \\
\text { COMMUNICATION that is problem- } \\
\text { solving based and timely. }\end{array}$ \\
\hline
\end{tabular}

Fig. 1. A team briefing designed to build relational coordination (RC) in an ad-hoc team.

a daily five-minute ritual, which in and of itself, likely has relational advantages at both micro-team and macro-organizational level. Watch our "OneTeam Practice" team briefing exercise for the case presented at the beginning of the article here. ${ }^{9}$

\section{CONCLUSION}

Relational coordination theory is a useful framework for understanding why briefings are essential to the performance of resuscitation teams. Deliberate efforts to target those briefings to maximize the rapid development of relational coordination at the micro level should be a priority. This critical step can be incorporated into the ZPS and readdressed throughout the resuscitation as indicated to optimize non-clinical processes and facilitate the ongoing coordination of care.

\section{CONFLICT OF INTEREST}

No potential conflict of interest relevant to this article was reported.

\section{REFERENCES}

1. Hicks $C$, Petrosoniak $A$. The human factor: optimizing trauma team performance in dynamic clinical environments. Emerg Med Clin North Am 2018;36:1-17.

2. Steinemann $S$, Bhatt $A$, Suares $G$, et al. Trauma team discord and the role of briefing. J Trauma Acute Care Surg 2016;81:184-9.

3. Carley S. \#stemlynsLIVE: five free strategies to improve your resuscitation practice [Internet]. St. Emlyn's; 2018 [cited 2019 Feb 15]. Available from: https://www.stemlynsblog.org/stemlynslive- 
five-free-strategies-to-improve-your-resuscitation-practice-stemlyns/.

4. Reid C, Brindley $P$, Hicks $C$, et al. Zero point survey: a multidisciplinary idea to STEP UP resuscitation effectiveness. Clin Exp Emerg Med 2018;5:139-43.

5. Haynes $A B$, Weiser TG, Berry WR, et al. A surgical safety checklist to reduce morbidity and mortality in a global population. N Engl J Med 2009;360:491-9.

6. Steinemann S, Berg B, Skinner A, et al. In situ, multidisciplinary, simulation-based teamwork training improves early trauma care. J Surg Educ 2011;68:472-7.

7. Gittell JH. High performance healthcare: using the power of relationships to achieve quality, efficiency and resilience. New York, NY: McGraw Hill; 2009.

8. Gittell JH. Transforming relationships for high performance. Stanford, CA: Stanford University Press; 2016.

9. Brazil V, Mutiloch J, Purdy E. OneTeam Practice: thinking ahead in resus [Internet]. YouTube; 2019 [cited 2019 Feb 15]. Available from: https://www.youtube.com/watch?v=wo_ $\mathrm{VPXVkbAA \& t}=2 \mathrm{~s}$.

10. Purdy El, McLean D, Alexander C et al. Doing our work better, together: a relationship-based approach to defining the quality improvement agenda in trauma care. BMJ Open Quality 2020; 9e000749 